OPEN ACCESS

Edited by:

Yandu Lu,

Hainan University, China

Reviewed by:

Taras P. Pasternak,

Albert Ludwigs University of Freiburg,

Germany

Abdulsamie Hanano, Atomic Energy Commission of Syria,

Syria

*Correspondence.

Guofeng Yang

yanggf@qau.edu.cn

tThese authors have contributed equally to this work.

Specialty section: This article was submitted to

Plant Biotechnology,

a section of the journal

Frontiers in Plant Science

Received: 15 February 2018

Accepted: 03 April 2018

Published: 17 April 2018

Citation:

Xu F, Fan Y, Miao F, Hu G-R, Sun J,

Yang $G$ and Li F-L (2018)

Naphthylacetic Acid and Tea

Polyphenol Application Promote

Biomass and Lipid Production

of Nervonic Acid-Producing

Microalgae. Front. Plant Sci. 9:506.

doi: 10.3389/fp/s.2018.00506

\section{Naphthylacetic Acid and Tea Polyphenol Application Promote Biomass and Lipid Production of Nervonic Acid-Producing Microalgae}

\author{
Feng $\mathrm{Xu}^{1,2+}$, Yong Fan ${ }^{2 t}$, Fuhong Miao ${ }^{1 \dagger}$, Guang-Rong $\mathrm{Hu}^{2}$, Juan Sun ${ }^{1}$, Guofeng Yang ${ }^{1 *}$ \\ and $\mathrm{Fu}-\mathrm{Li} \mathrm{Li}^{2}$
}

\begin{abstract}
${ }^{1}$ Forage Research and Development Center for Arable Region, Qingdao Agricultural University, Qingdao, China, ${ }^{2}$ Shandong Provincial Key Laboratory of Synthetic Biology, Qingdao Institute of Bioenergy and Bioprocess Technology, Chinese Academy of Sciences, Qingdao, China
\end{abstract}

Mychonastes afer HSO-3-1 is a potential producer of nervonic acid, which could be accumulated to $2-3 \%$ of dry cell weight. Improving the productivity of nervonic acid is critical to promote the commercialization of this product. In this study, 1-naphthylacetic acid (NAA) and tea polyphenol (TP) were selected as bioactive additives to stimulate the growth of $M$. afer. Supplementing NAA in the early growth stage and TP in the middle and late growth stage led to improved lipid accumulation in $M$. afer. The cultures supplemented with TP at the late growth stage maintained higher photosynthetic efficiency than the control groups without TP. Furthermore, the intracellular reactive oxygen species (ROS) accumulations in $M$. afer supplemented with $500 \mathrm{mg} / \mathrm{L}$ of TP was $63 \%$ lower than the control group. A linear relationship $\left(R^{2}=0.899\right)$ between the values of $\mathrm{Fv} / \mathrm{Fm}$ and ROS accumulation was established. We hypothesize supplement of bioactive additives at different growth stage could promote the cell growth rate and nervonic acid productivity of $M$. afer by retrieving intracellular ROS level. Further analysis of photosynthetic system II (PSII) protein in M. afer cultured in presence of NAA and TP indicated the levels of D1 and D2 proteins, the core skeleton proteins of PSII, showed 33.3 and $25.6 \%$ higher than the control group. CP43 protein, a critical module in PSII repair cycle, decreased significantly. These implied that TP possesses the function of slowing down the damage of PSIl by scavenging excess intracellular ROS.

Keywords: Mychonastes afer, photosynthetic efficiency, reactive oxygen species, photosynthetic system II, CP43, bioactive additive

\section{INTRODUCTION}

As a promising feed-stock of biodiesel or jet fuel, microalgae have received extensive attention in recent years due to its ability of producing substantial amounts of triacylglycerols (TAGs) under stress conditions (Hu et al., 2008). The concept of using microalgae as an alternative and renewable source of lipid-rich biomass feed-stock for biodiesel has been explored over the past few decades, while technical and economic barriers still limit the development of the whole industry chain (Williams and Laurens, 2010). Outstanding strains with high lipid yield and effective culture technology are main challenges for commercialization of microalgal biodiesel (Chisti, 2007). 
Mychonastes afer HSO-3-1 is a promising candidate for biodiesel production, because of its high lipid content $(50 \%$ dry cell weight) and fast growth rate. Furthermore, nervonic acid (NA, C24:1 $\Delta 15$, cis-tetracos-15-enoic acid, $\omega-9$ ) could account for more than $5 \%$ of the neutral fatty acids in M. afer. NA, a very long chain monounsaturated fatty acid (VLMFA), is essential for brain development (Sandhir et al., 1998; Yuan et al., 2011; Fan et al., 2018b). It could be used to treat genetic disorders of the lipid metabolism, such as Zellweger syndrome or adrenoleukodystrophy (Coupland and Langley, 1993; Fan et al., 2018a). An impairment in the provision of NA in demyelinating diseases (like multiple sclerosis) suggests that a diet rich with NA could improve the treatment (Sargent et al., 1994).

In order to increase the productivity of NA in $M$. afer, optimization of the culture conditions should be developed firstly. Phytohormones are found not only in higher plants but also in algae, and the biological activities of hormones in algae are similar to the functions of hormones in higher plant ( $\mathrm{Lu}$ and $\mathrm{Xu}$, 2015). Exogenous IAA $(0.1-10 \mu \mathrm{M})$ increased Chlamydomonas reinhardtii biomass production by 54-69\% (Park et al., 2013). The supplement of IAA $(0.1 \mu \mathrm{M})$ or 1-naphthylacetic acid (NAA) $(1 \mu \mathrm{M})$ induced a significant increase in cell number by 53 and $24 \%$ in Chlorella vulgaris, and it would increase the amount of monosaccharides, photosynthetic pigments, and soluble enzymes in C. vulgaris (Piotrowska-Niczyporuk and Bajguz, 2014).

Compound additives will be a trend in the cultivation process, and the combination of additives needs to be analyzed and tried unceasingly. According to our previous research, intracellular reactive oxygen species (ROS) level is another key factor that influences the growth of microalgae. Plants maintain complex systems of overlapping antioxidants to balance the oxidative state in vivo (Munne-Bosch, 2005), while microalgal antioxidant system may not deal with the over-oxidation stress efficiently due to its simple cell structure (Cavas and Yurdakoc, 2005). Reactive oxygen species can function as signaling molecules that control the cellular basal metabolism such as induced cell re-programming toward programmed cell death or many other developmental processes. Unbalanced oxidative state will cause abiotic stress responses in plants, and excess ROS accumulation is toxic to cells (Mittler, 2002). Antioxidants can prevent cells from ROS accumulation by scavenging the excessive ROS (Wolf, 2005). In addition, algal antioxidant system plays crucial roles in stress tolerance, like heavy metal, salinity and heat stress (Geider et al., 1993; Pinto et al., 2003; Liu and Pang, 2010). In our previous work, varieties of potential candidate additives were selected from phytohormones and antioxidants, like NAA, indole-3-acetic acid, gibberellic acid, kinetin, abscisic acid, tocopherol, epigallocatechin-3-gallate (EGCG), and tea polyphenol (TP) (Frei and Higdon, 2003). In consideration of solubility, stability, and photo-sensitivity, one phytohormone (NAA) and two antioxidants (EGCG and TP) were finally selected for further investigation of the effects on the growth and lipid accumulation of $M$. afer. We hypothesize that the supplement of bioactive additives at different growth stages could promote the cell growth rate and nervonic acid productivity of $M$. afer. Orthogonal experiments were used to analyze the additive doses, and it was further confirmed by single factor experiment analysis.
We found that the supplement of these additives at different growth stages led to different effects on microalgal growth. Interestingly, supplement of TP increases the tolerance to ROS in $M$. afer at later growth stage. Photosynthetic efficiency of the cells cultured in presence of NAA and TP was analyzed.

\section{MATERIALS AND METHODS}

\section{Strains and Culture Conditions}

Mychonastes afer was stored in the China General Microbiological Culture Collection Center with the identifying code CGMCC No. 4654. It was cultured in a column photobioreactor $(20 \mathrm{~cm}$ high, $4 \mathrm{~cm}$ diameter, $100 \mathrm{~mL}$ culture volume) under continuous illumination at light intensity of $120 \mu \mathrm{mol}$ photons $\mathrm{m}^{-2} \cdot \mathrm{s}^{-1}$. Culture mixing and aerating was provided by aeration with filter-sterilized air containing 2\% $\mathrm{CO}_{2}$ (Yuan et al., 2017). The initial $\mathrm{OD}_{750}$ of algal culture was 1.0. All strains were cultured at room temperature $\left(25 \pm 2{ }^{\circ} \mathrm{C}\right)$ for 12 days. The cells were grown in a modified BG-11 medium with $0.374 \mathrm{~g} / \mathrm{L} \mathrm{NaNO}_{3}$ ( $\mathrm{Li}$ et al., 2011). The other compositions of the BG-11 medium are as follows: $0.03 \mathrm{~g} / \mathrm{L} \mathrm{K}_{2} \mathrm{HPO}_{4}, 0.075 \mathrm{~g} / \mathrm{L} \mathrm{MgSO}_{4} \cdot 7 \mathrm{H}_{2} \mathrm{O}$, $0.036 \mathrm{~g} / \mathrm{L} \mathrm{CaCl}{ }_{2} \cdot 2 \mathrm{H}_{2} \mathrm{O}, 0.006 \mathrm{~g} / \mathrm{L}$ citric acid, $0.006 \mathrm{~g} / \mathrm{L}$ ferric ammonium citrate, $0.001 \mathrm{~g} / \mathrm{L}$ EDTA, $0.02 \mathrm{~g} / \mathrm{L} \mathrm{Na} \mathrm{CO}_{3}$. And $1 \mathrm{ml}$ of trace metal solution per liter medium, which content: $2.86 \mathrm{~g} / \mathrm{L} \mathrm{H}_{3} \mathrm{BO}_{3}, 1.81 \mathrm{~g} / \mathrm{L} \mathrm{MnCl}_{2} \cdot 4 \mathrm{H}_{2} \mathrm{O}, 0.222 \mathrm{~g} / \mathrm{L} \mathrm{ZnSO}_{4} \cdot 7 \mathrm{H}_{2} \mathrm{O}$, $0.39 \mathrm{~g} / \mathrm{L} \mathrm{NaMoO} \mathrm{NaH}_{2} \mathrm{O}, 0.079 \mathrm{~g} / \mathrm{L} \mathrm{CuSO}_{4} \cdot 5 \mathrm{H}_{2} \mathrm{O}, 0.0494 \mathrm{~g} / \mathrm{L}$ $\mathrm{Co}\left(\mathrm{NO}_{3}\right)_{2} \cdot 6 \mathrm{H}_{2} \mathrm{O}$. The culture medium was sterilized in an autoclave at $121^{\circ} \mathrm{C}$ for $20 \mathrm{~min}$. TP (Food grade, Xitang Biological Technology, Co., Ltd., China), EGCG and NAA (TCI Development, Co., Ltd., Shanghai, China) were sterilized by filtration.

In the first step, orthogonal experiments were carried out with four levels as follows: $0 \mathrm{mg} / \mathrm{L}\left(\mathrm{A}_{1}\right), 0.5 \mathrm{mg} / \mathrm{L}\left(\mathrm{A}_{2}\right), 1.5 \mathrm{mg} / \mathrm{L}\left(\mathrm{A}_{3}\right)$, and $5 \mathrm{mg} / \mathrm{L}\left(\mathrm{A}_{4}\right)$ for NAA dosage, $0 \mathrm{mg} / \mathrm{L}\left(\mathrm{B}_{1}\right), 0.5 \mathrm{mg} / \mathrm{L}$ EGCG $\left(\mathrm{B}_{2}\right), 2 \mathrm{mg} / \mathrm{L} \mathrm{TP}\left(\mathrm{B}_{3}\right)$, and $20 \mathrm{mg} / \mathrm{L} \mathrm{TP}\left(\mathrm{B}_{4}\right)$ for antioxidants dosage. And $120 \mu \mathrm{mol}$ photons $\mathrm{m}^{-2} \cdot \mathrm{s}^{-1}$ of light intensity was used as low-light level (LL, $\left.\mathrm{C}_{1} / \mathrm{C}_{2}\right), 400 \mu \mathrm{mol}$ photons $\mathrm{m}^{-2} \cdot \mathrm{s}^{-1}$ was used as high-light level $\left(\mathrm{HL}, \mathrm{C}_{3} / \mathrm{C}_{4}\right)$. Three-factors-fourlevels experiments were conducted by the orthogonal list $L_{16}\left(4^{5}\right)$. NAA was added at the early growth stage when the $\mathrm{OD}_{750}$ of algal culture was about 3.0 at day 2. EGCG and TP were added at the middle growth stage when the $\mathrm{OD}_{750}$ of algal culture was about 6.0 at day 6. Experimental scheme and results were shown in Supplementary Table 1. All data were analyzed by SPSS Statistics (Version 19, IBM, Armonk, NY, United States).

To confirm the effects of the candidate factors selected by orthogonal experiments, single factor experimental scheme was conducted with a wider gradient of the additive concentration. A new range of NAA concentrations $(0,0.1$, and $10 \mathrm{mg} / \mathrm{L})$ and TP concentrations $(0,50$, and $500 \mathrm{mg} / \mathrm{L})$ were chosen. Nine experimental groups were as follows: CT, 0.1 NAA, 10 NAA, 50 TP, $500 \mathrm{TP}, 0.1 \mathrm{NAA}+50 \mathrm{TP}, 0.1 \mathrm{NAA}+500 \mathrm{TP}, 10 \mathrm{NAA}+50$ $\mathrm{TP}$, and $10 \mathrm{NAA}+500 \mathrm{TP}$. An additive combination of NAA $(0.1 \mathrm{mg} / \mathrm{L})$ and TP $(500 \mathrm{mg} / \mathrm{L})$ in the medium was expressed as $0.1 \mathrm{NAA}+500 \mathrm{TP}$. CT was the control group without additives. 


\section{Algal Biomass and Chlorophyll Fluorescence Measurements}

Algal samples $(10 \mathrm{~mL})$ were filtered through the pre-weighed filter paper $(0.22 \mathrm{~mm}$, Whatman International, Ltd., Maidstone, United Kingdom) and dried at $105^{\circ} \mathrm{C}$ for $8 \mathrm{~h}$. The difference between the final weight and initial weight of the filter paper was the dry weight of the samples.

Algal cells suspension was transferred to the 96-well plates and analyzed by Imaging-PAM Chlorophyll Fluorometer (Walz, Effeltrich, Germany). The chlorophyll fluorescence was measured and calculated, the data of photosynthetic efficiency were determined, including the data of $\mathrm{Fv} / \mathrm{Fm}$, non-photochemical quenching (NPQ) and quantum yield of photochemical energy conversion in PSII (YII) (Klughammer and Schreiber, 2008; Hu et al., 2013).

\section{Lipid Extraction, Quantification, and Composition Analysis}

Nile red staining was carried out for measurement of neutral lipids in microalgae (Chen et al., 2009). Freeze-dried biomass was further used for total lipid extraction (Bigogno et al., 2002). Following procedures: $30 \mathrm{mg}$ dry algae powder was resuspended with the chloroform-methanol (4 vs. $2 \mathrm{ml}$ ) to extract the lipid by shaking with a speed of $200 \mathrm{rpm}$ at $37^{\circ} \mathrm{C}$ for $2 \mathrm{~h}$. After centrifuging at $3200 \mathrm{~g}$ for $10 \mathrm{~min}$, the supernatant was transferred to a new tube and mixed with $2 \mathrm{ml}$ methanol and $3.6 \mathrm{ml} \mathrm{5 \%}$ $\mathrm{NaCl}$. The remaining lipid was dissolved in chloroform phase by centrifuging at $3200 \mathrm{~g}$ for $5 \mathrm{~min}$, then the chloroform phase was transferred into pre-weight vials. The residuals were weighed after removing chloroform by nitrogen evaporator.

Total lipid composition was analyzed after methyl esterification processing by reacting with $2 \% \mathrm{H}_{2} \mathrm{SO}_{4}$ in methanol at $85^{\circ} \mathrm{C}$ for $3 \mathrm{~h}$. Gas chromatography analysis was carried out with a GC system (7890A, Agilent Technologies, Inc., Santa Clara, CA, United States). HP-5 (30 m $\times 320 \mu \mathrm{m} \times 0.25 \mu \mathrm{m}$, Agilent, United States) was selected as the chromatographic column. Gas heating process was as follows: rise the column temperature to $190^{\circ} \mathrm{C}$ with a heat rate of $10^{\circ} \mathrm{C} / \mathrm{min}$, and maintain $1 \mathrm{~min}$. Then rise the temperature to $207^{\circ} \mathrm{C}$ with a heat rate of $0.8^{\circ} \mathrm{C} / \mathrm{min}$, and maintain $1 \mathrm{~min} . \mathrm{N}_{2}$ was used as carrying gas with a speed $(28.5 \mathrm{~mL} / \mathrm{min})$ and split ratio $(10: 1, v / v)$. Heptadecanoic acid $(\mathrm{C} 17: 0,3 \mathrm{mg} / \mathrm{mL})$ was used as an internal standard.

\section{Intracellular ROS Level, Lipid Peroxidation, and ROS Scavenging Enzyme (Catalase) Activity Analysis}

Intracellular ROS analysis was performed by using a Reactive Oxygen Species Assay Kit (Beijing Solarbio Science \& Technology, Co., Ltd., China; code: CA1410-100T) according to the manufacturer's instructions. This kit used 2,7-Dichlorodihydrofluorescein diacetate (DCFH-DA) as probe. This non-fluorescence probe could be oxidized by intracellular ROS, including hydrogen peroxide $\left(\mathrm{H}_{2} \mathrm{O}_{2}\right)$ and hydroxyl radicals $(\mathrm{OH} \bullet)$, to the fluorescence probe of DCF. This fluorescence was most sensitive to the level of $\mathrm{H}_{2} \mathrm{O}_{2}$ and could be used to compare the levels of this ROS in different conditions of the cells. Culture samples of $M$. afer were collected and adjusted to a final cell concentration of $1 \times 10^{7}$ cells per milliliter with culture medium which collected from the culture system. Then cells were incubated with $1 \mu \mathrm{M}$ DCFH-DA for 20 min under culture condition (same light intensity and temperature). DCF fluorescence was measured with $488 \mathrm{~nm}$ excitation wavelength and $525 \mathrm{~nm}$ emission wavelength by a multi-mode microplate reader (SynergyTM HT, BioTek, Winooski, VT, United States).

Malondialdehyde (MDA, the by product of lipid peroxidation) content and Catalase (CAT) activities were measured according to Shi et al. (2009). MDA and CAT kits were purchased from Nanjing Bioengineering Institute, China.

\section{Thylakoid Membrane Preparation and Protein Level Analysis}

Microalgae cells were harvested by centrifugation at $4000 \mathrm{~g}$ for $10 \mathrm{~min}$ and resuspended in $10 \mathrm{ml}$ of Hepes-OH buffer (20 mM, pH 7.5). After centrifuged at $3200 \mathrm{~g}$ for $5 \mathrm{~min}$, the pellets were suspended with $5 \mathrm{ml}$ of extraction buffer (300 mM sorbitol; $50 \mathrm{mM}$ Hepes-OH, pH 7.5; $2 \mathrm{mM}$ $\mathrm{Na}_{2}$ EDTA, $\mathrm{pH} 8.0 ; 1 \mathrm{mM} \mathrm{MgCl} \cdot 6 \mathrm{H}_{2} \mathrm{O}$ and $\left.1 \% \mathrm{BSA}\right)$. The microalgae cells were homogenized by grinding in liquid nitrogen and the extraction were performed in triplicates. All subsequent steps were carried out on ice. The supernatant was collected in centrifuge tube by centrifugation at $4000 \mathrm{~g}$ for $10 \mathrm{~min}$. Following centrifugation at $13000 \mathrm{~g}$ for $30 \mathrm{~min}$ with the collected supernatant, the precipitated thylakoid membranes were resuspended in extraction buffer.

For the qualification of chlorophyll and protein content in thylakoid, thylakoid membrane was soaked with $80 \%$ acetone at $60^{\circ} \mathrm{C}$ for $2 \mathrm{~h}$, then separate the chlorophyll and protein by centrifugation at $13000 \mathrm{~g}$ for $15 \mathrm{~min}$. Chlorophyll content in thylakoid was determined by the method published (Wellburn, 1994). And the total protein content was determined by BCA Protein Assay Kit (by protein reduction chromogenic reaction) following the manufacturer's instructions (Beijing Solarbio Science \& Technology, Co., Ltd., China).

Sodium dodecyl sulfate polyacrylamide gel electrophoresis (SDS-PAGE) was performed according to the protocol (Ikeuchi and Inoue, 1988), and thylakoid membrane proteins were used as testing samples. For semi-quantification analysis, the gray scale of each band was measured by Image J software. Target bands which had significant differences were excised and decolorized using decolor-buffer ( $100 \mathrm{mM} \mathrm{NH}_{4} \mathrm{CO}_{3} / 30 \%$ acetonitrile) at $4^{\circ} \mathrm{C}$ for $2 \mathrm{~h}$. This step was repeated two times until the spot gels were totally clean. After centrifugation at $13800 \mathrm{~g}$ for $5 \mathrm{~min}$, the pellets of gels were lyophilized and then transferred in $5 \mu \mathrm{l}$ Trypsin solution $\left(12.5 \mathrm{ng} / \mu \mathrm{l}\right.$ in $\left.50 \mathrm{mM} \mathrm{NH} \mathrm{HCO}_{3}\right)$ at $4^{\circ} \mathrm{C}$ for $60 \mathrm{~min}$, followed by adding $20 \mu \mathrm{l} 50 \mathrm{mM} \mathrm{NH} \mathrm{HCO}_{3}$ at $37^{\circ} \mathrm{C}$ for $20 \mathrm{~h}$. The enzymatic hydrolysate was transferred to another tube, and the supernatant was used for LC-MS/MS analysis.

Samples were analyzed on a Surveyer plus a LC-LTQ XL (Thermo Fisher Scientific, Inc., Waltham, MA, United States). The electrospray voltage of $2.2 \mathrm{kV}$ was carried out with the ion transfer tube temperature at $220^{\circ} \mathrm{C}$. Digested peptides were 
analyzed by using data-dependent acquisition of a MS scan $(600-2000 \mathrm{~m} / \mathrm{z})$, and then MS/MS scans were performed for the three most abundant ions in each MS scan. Normalized collision energy for MS/MS was set to $35 \%$ with an isolation width of $1.5 \mathrm{amu}$. From raw files, MS/MS spectra were exported to individual files in data format according to the following setup: peptide mass range, 350-5000 $\mathrm{Da}$; minimal total ion intensity threshold, 1000; minimal number of fragment ions, 15; precursor mass tolerance, 1.4 amu; group scan, 1 ; minimum group count, 1.

Extracted MS/MS spectra were converted to a Mascot genetic format file (mgf) and searched against a C. reinhardtii database [from the National Center for Biotechnology Information (NCBI), updated November 17, 2017, containing 33,220 entries] or Swiss_Prot (updated November 17, 2017, containing 560,836 entries) by Mascot (Version 2.4, Matrix Science, Ltd., London, United Kingdom).

For western-blot analysis, thylakoid membrane proteins of M. afer were used as total protein samples. Primary antibodies [D1 protein of photosynthetic system II (PSII), C-terminal, rabbit antibody, code: AS05_084] were purchased from Agrisera, Co., Ltd., Sweden. Western-blotting was performed by probing with specific antibodies after electroblotting onto nitrocellulose membranes (GE Healthcare, Co., Ltd., Chicago, IL, United States) (Liu et al., 2012b). Primary antibody was diluted 10000-fold (antibody against D1), and signals from horseradish peroxidaseconjugated goat anti-rabbit $\operatorname{IgG}(\mathrm{H}+\mathrm{L})$ were visualized using Clarity Western ECL substrate (MDBio, Inc., Qingdao, China) and the blotting-spots were analyzed using ImageJ software (National Institutes of Health, United States) (Liu et al., 2012a).

\section{Statistical Analysis}

All the experiments were repeated three times. Unless otherwise stated, all data were expressed as mean standard deviation (SD). Statistical significance and determination coefficients of the values obtained from each experiment was evaluated by variance (ANOVA) using the software SPSS (version 19.0, IBM, Chicago, IL, United States). Significant differences were considered when $p<0.05$.

\section{RESULTS}

\section{Growth and Lipid Content of $M$. afer After NAA and Antioxidants Supplement}

Experimental scheme and results of the orthogonal experiments were shown in Supplementary Table 1. Light intensity, NAA and antioxidants all had significant $(p<0.05)$ influence on M. afer photosynthetic efficiency (Supplementary Table 3), while the growth was only significantly $(p=0.001)$ affected by light intensity (Supplementary Table 2). No significant effect on lipid content was observed from all of these factors (Supplementary Table 4). Microalgal photosynthetic efficiencies were significantly influenced by NAA $(p=0.046)$ and antioxidants $(p=0.033)$, while these effects were not reflected by the growth of $M$. afer (Figure 1).

Based on the relationship between photosynthetic efficiency of M. afer and additives, new experimental scheme was conducted

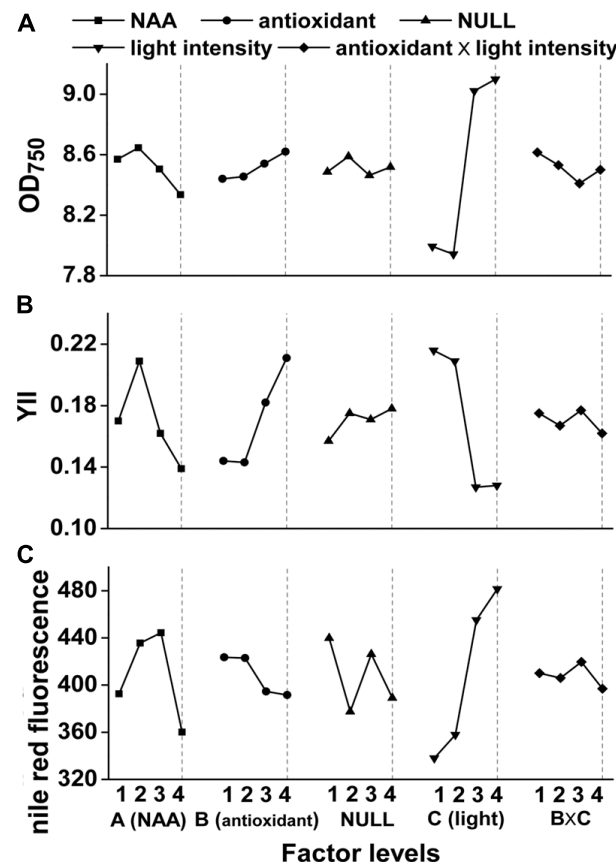

FIGURE 1 | Orthogonal effect curves of NAA, antioxidants, and light intensity on growth $\left(\mathrm{OD}_{750}\right)$, photosynthetic efficiency $(\mathrm{YII})$, and lipid accumulation of Mychonastes afer. NAA (A), antioxidant (B), light intensity (C) and the interactions between the light intensity and antioxidants $(B \times C)$ were the factors investigated here with four levels, and NULL is for the error assessment. The four levels of these factors were as follows: $0 \mathrm{mg} / \mathrm{L}\left(\mathrm{A}_{1}\right)$, $0.5 \mathrm{mg} / \mathrm{L}\left(\mathrm{A}_{2}\right), 1.5 \mathrm{mg} / \mathrm{L}\left(\mathrm{A}_{3}\right)$, and $5 \mathrm{mg} / \mathrm{L}\left(\mathrm{A}_{4}\right)$ for NAA dosage, $0 \mathrm{mg} / \mathrm{L}\left(\mathrm{B}_{1}\right)$, $0.5 \mathrm{mg} / \mathrm{L}$ EGCG $\left(B_{2}\right), 2 \mathrm{mg} / \mathrm{L}$ TP $\left(B_{3}\right)$, and $20 \mathrm{mg} / \mathrm{L}$ TP $\left(B_{4}\right)$ for antioxidants dosage. And $120 \mu \mathrm{mol}$ photons $\mathrm{m}^{-2} \cdot \mathrm{s}^{-1}$ of light intensity was used as low-light level $\left(\mathrm{LL}, \mathrm{C}_{1} / \mathrm{C}_{2}\right), 400 \mu \mathrm{mol}$ photons $\mathrm{m}^{-2} \cdot \mathrm{s}^{-1}$ was used as high-light level $\left(\mathrm{HL}, \mathrm{C}_{3} / \mathrm{C}_{4}\right)$.

with a wider gradient of the additive concentration to further verify the orthogonal experiment results. The algal growth rate increased with an addition of $0.1 \mathrm{mg} / \mathrm{L}$ NAA on the 2nd day of cultivation, and this promotion was amplified when TP was added on the 6th day of cultivation. After the supplement of NAA $(0.1 \mathrm{mg} / \mathrm{L})$ and TP $(500 \mathrm{mg} / \mathrm{L})$ in the medium, the maximum algal biomass was $3.69 \mathrm{~g} / \mathrm{L}$, which was $18.76 \%$ higher $(p=0.002)$ than control (Figure 2A).

Total lipid content of $M$. afer was increased with the supplementary of $0.1 \mathrm{mg} / \mathrm{L}$ NAA and TP. The maximum algal total lipid content and lipid yield was 17.6 and 39.6\% higher than control without additives, respectively. It appeared in the experimental group with the supplement of NAA $(0.1 \mathrm{mg} / \mathrm{L})$ and TP $(500 \mathrm{mg} / \mathrm{L})$ in the medium (Figure 2B). However, no significant difference of fatty acids composition was observed under different culture conditions, according to the GC analysis data (Supplementary Table 5).

\section{Effects of NAA and TP on Photosynthetic Efficiency of $M$. afer}

Microalgae utilize light energy to maintain the energy requirements for life activities and growth. In order to elucidate 

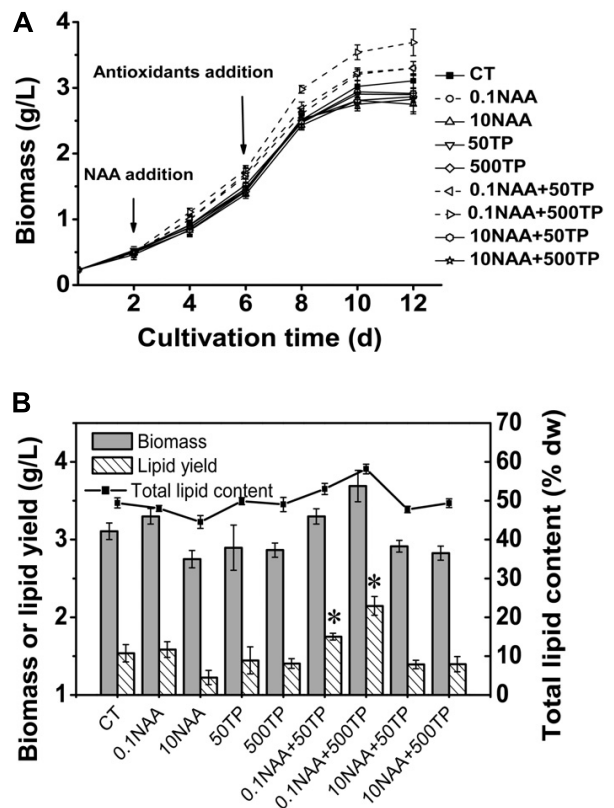

FIGURE 2 | Growth and lipid content of $M$. afer supplemented with NAA and TP. (A) Growth curves of $M$. afer that grew under different treatment of additive combinations. CT is the control group without additives. NAA and TP were added at day 2 and day 6 , respectively. (B) Final algal biomass (dry weight), lipid content (\% dry weight), and lipid yield of $M$. afer under different culture conditions. Values are means $\pm \mathrm{SE}(n=3)$. Asterisks indicate statistically significant differences compared with the control group ( ${ }^{*} p<0.05$; ANOVA).

the mechanism for the higher growth rate and lipid content of M. afer after adding NAA and TP, the photosynthetic efficiency of $M$. afer under different culture conditions were measured. Fv/Fm was the potential maximum photosynthetic activity of the photosynthetic organisms. Fv/Fm could also reflect the activity of the PSII complex. YII stands for the actual quantum yield (actual photosynthetic efficiency) of PSII in any light state and can reflect the activity of linear electron transport (Klughammer and Schreiber, 2008). NPQ reflects the ability of photosynthetic organisms to dissipate excess light to heat. The Fv/Fm and YII of $M$. afer decreased in the later stage of culture, while some groups which added TP at day 6 showed higher Fv/Fm than control group $(p=0.002)$. Consequently, the NPQ of $M$. afer increased in the later stage of culture, while the groups added with TP would lead a lower NPQ, indicating a lesser light energy dissipation in the cells with TP supplement (Figure 3). These results suggested that $\mathrm{TP}$ could maintain higher photosynthesis efficiency of $M$. afer at later growth stage compared with the control group.

\section{Intracellular Reactive Oxygen Species (ROS), Lipid Peroxidation, and ROS Scavenging Enzyme (CAT) Activity Analysis}

At the late growth stage, algae grew under stress conditions due to deplete of nutrition in medium, which in general led to decreased

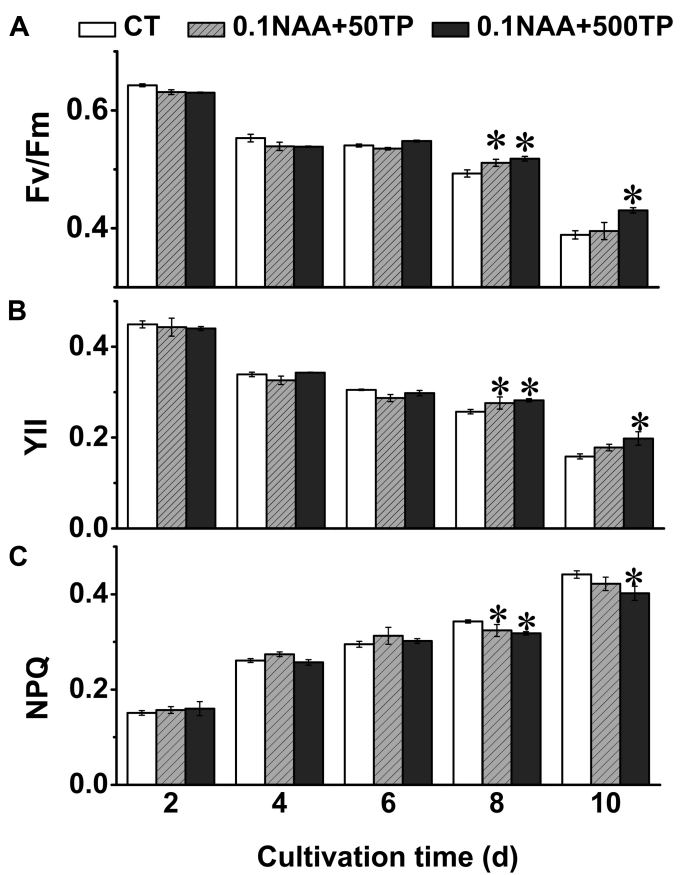

FIGURE 3 | Effects of NAA and TP on photosynthetic efficiency of $M$. afer. Photosynthetic parameters Fv/Fm (A), YII (B), and NPQ (C) were detected. NAA and TP were added at day 2 and day 6 , respectively. Values are means \pm SE $(n=3)$. Asterisks indicate statistically significant differences compared with the control group ( ${ }^{*} p<0.05$; ANOVA).

energy converting efficiency (Kolber et al., 1988). Excess light energy would lead to sustained increases in intracellular ROS level, which would have detrimental effects on algal growth (Choo et al., 2004). The observation that cells of $M$. afer could maintain high photosynthetic efficiency at later growth stage after TP supplement, implying that TP might regulate the photosynthesis efficiency of $M$. afer by alleviating its intracellular ROS. We selected day 8 as the time point to analyze the relationship between photosynthetic efficiency of $M$. afer and its intracellular ROS level, because the photosynthetic efficiency of $M$. afer showed the most significant difference between the control group and the cells cultured with $0.1 \mathrm{mg} / \mathrm{L} \mathrm{NAA}$ and $500 \mathrm{mg} / \mathrm{L}$ TP at this time point $(p=0.0004)$. A linear relationship was observed between Fv/Fm values and intracellular ROS levels, which suggested that TP could promote the photosynthesis efficiency of $M$. afer by alleviating its intracellular ROS at later growth stage (Figures 4A,B). Base on the method, the species of these reactive oxygen were mainly $\mathrm{H}_{2} \mathrm{O}_{2}$. The cells of two experimental groups (0.1 NAA+50 TP and 0.1 NAA+500 TP) which had the highest lipid yield were harvested for further MDA content and CAT activities analysis. MDA is the by product of lipid peroxidation. MDA content was analyzed as the indicator for lipid peroxidation, and the excess ROS accumulation in cells can be represented by their lipid peroxidation (Zhang et al., 2013). CAT is a key enzyme which is located in peroxisomes and mitochondria in ROS scavenging system (Kato et al., 1997). CAT became more abundant in the later stage of the 


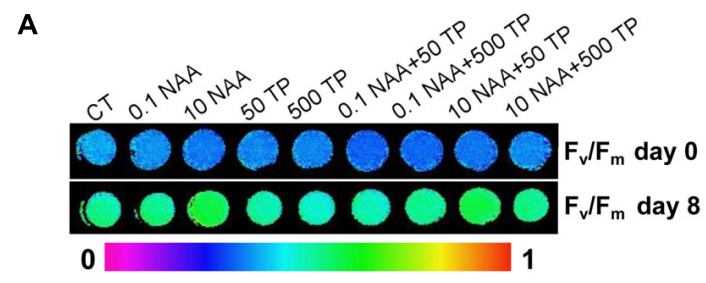

B

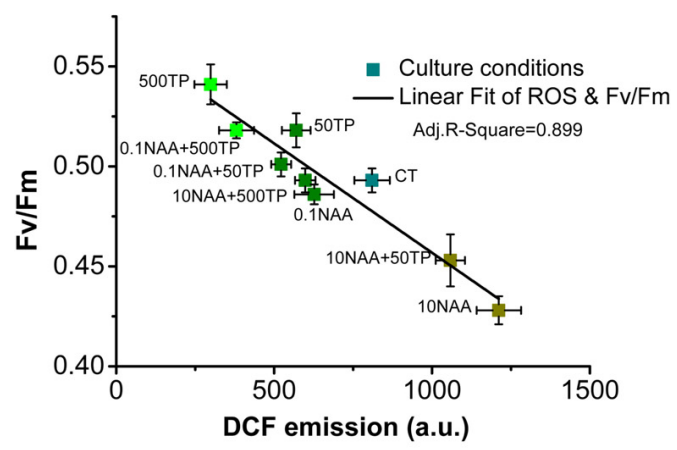

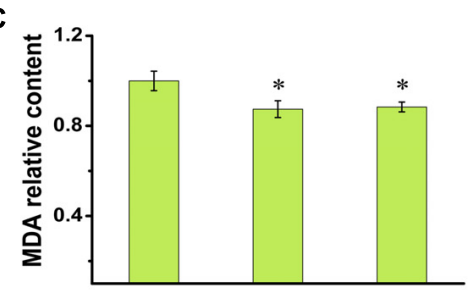

D

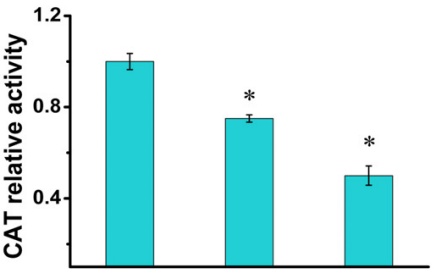

E

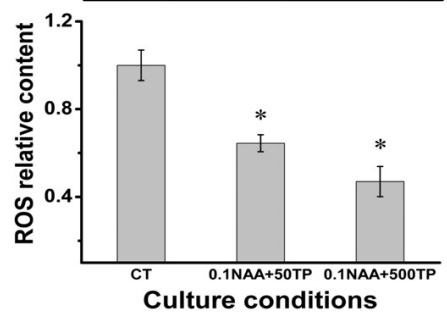

FIGURE 4 | Intracellular ROS analysis of M. afer and their relationship with the Fv/Fm values under different culture conditions. (A) False-color images showed Fv/Fm variations of $M$. afer under different culture conditions. Algal cells suspension was added to the 96 -well plates. After 10 min of dark adaptation, Fv/Fm was determined following a saturating pulse of light, and chlorophyll fluorescence images of algal cells suspension were obtained at this time point. (B) Linear fit of ROS and Fv/Fm. DCF fluorescence was used to semi-quantitative analyze the accumulation of $\mathrm{H}_{2} \mathrm{O}_{2}$ in $M$. afer. Quantification analysis of intracellular ROS level (C), MDA content (D), and CAT activity (E) of $M$. afer under different culture conditions. $M$. afer cells were harvested and analyzed immediately at day 8. Values are means \pm SE $(n=3)$. Asterisks indicate statistically significant differences compared with the control group $\left({ }^{*} p<0.05\right.$; ANOVA).

cell culture, and higher CAT activity reflected a later stage of the cell culture. Over-expression of CAT in cytosolic or mitochondrial compartment protects cells against oxidant injury (Bai et al., 1999). Intracellular ROS level (DCF fluorescence) of M. afer cultured with NAA $(0.1 \mathrm{mg} / \mathrm{L})$ and TP $(500 \mathrm{mg} / \mathrm{L})$ were significantly lower than the control group, which decreased $53 \%$ (Figure 4C). Correspondingly, MDA content and CAT activity of M. afer cultured with NAA $(0.1 \mathrm{mg} / \mathrm{L})$ and TP $(500 \mathrm{mg} / \mathrm{L})$ were about 88.4 and $50 \%$ compared with control group, respectively (Figures 4D,E). The lower intracellular ROS level and MDA content indicated that the cells of $M$. afer cultured with TP supplement were under lower oxidant stress than the control group. Meanwhile, a lower CAT activity was enough for excessive ROS neutralization in TP supplemented cultures.

\section{Western-Blot Analysis of Photosynthetic Proteins}

The cells of two experimental groups $(0.1 \mathrm{NAA}+50 \mathrm{TP}$ and 0.1 $\mathrm{NAA}+500 \mathrm{TP}$ ) which had the highest lipid yield were harvested for further quantification analysis of photosynthetic proteins. As the core photosynthetic apparatus of PSII, the abundance of chloroplast photosynthetic protein D1 could represent the amount of functional PSII in algal cells (Schnettger et al., 1994). According to the western-blot result, D1 content in the cells that cultured with $0.1 \mathrm{mg} / \mathrm{L} \mathrm{NAA}$ and $500 \mathrm{mg} / \mathrm{L}$ TP supplement was $33.3 \%$ higher than control (Figures 5A,B). Dilutions of control group were used to proving the accuracy of western-blotting process. Combined with the ROS level results, it is speculated that the cells with higher TP supplement were suffered less oxidant damage on the PSII.

In order to get more clues about how TP induced the high robust of PSII to response to high ROS stress, thylakoid membrane proteins were analyzed by SDS-PAGE. Four bands at $24,25,27$, and $50 \mathrm{kDa}$ were chosen for further composition and semi-quantification analysis (Supplementary Figure 1). Based on our western-blotting experience of D1 protein (two bands with close dimensions at $25 \mathrm{kDa}$ ), bands at 24 and $25 \mathrm{kDa}$ are $\mathrm{D} 1$ and $\mathrm{pD} 1$ proteins (precursor $\mathrm{D} 1$ protein), respectively. Two bands at 50 and $27 \mathrm{kDa}$ exhibit significant differences between the treatment samples and control by the gray scale analysis of blue Coomassie-stained gel (Figure 5D). Further LC-MS/MS analysis predicted these are the protein bands of CP43 (PSBC_CHLEU) and D2 (PSBD_BIGNA), respectively (Figure 5D and Supplementary Table 6). With TP supplement, the amount of D2 protein was $25.6 \%$ higher than control, while the amount of CP43 was $84.2 \%$ lower than control (Figures 5C,D).

\section{DISCUSSION AND CONCLUSION}

Auxins play a particular role in higher plant development by affecting several physiological processes 
A
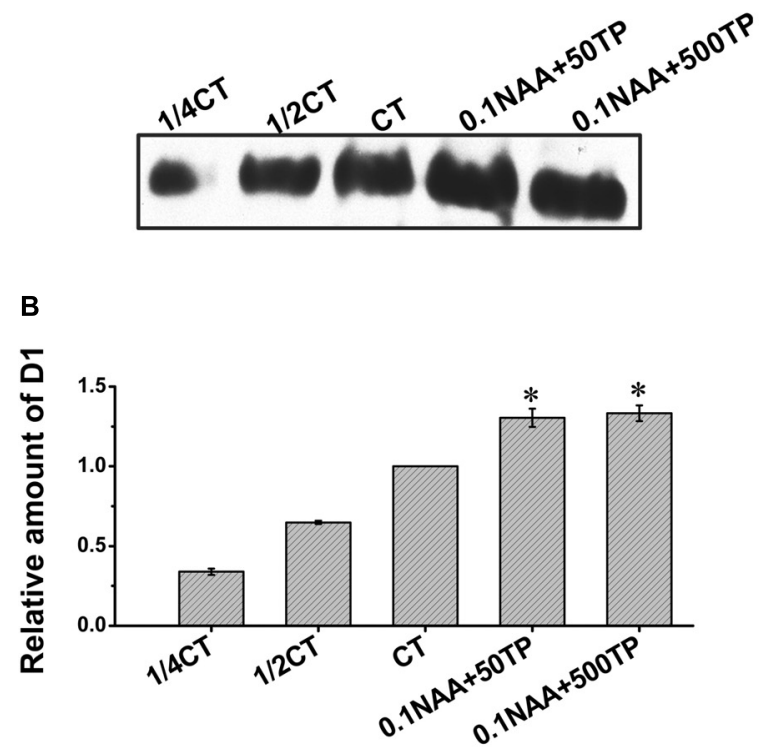

C

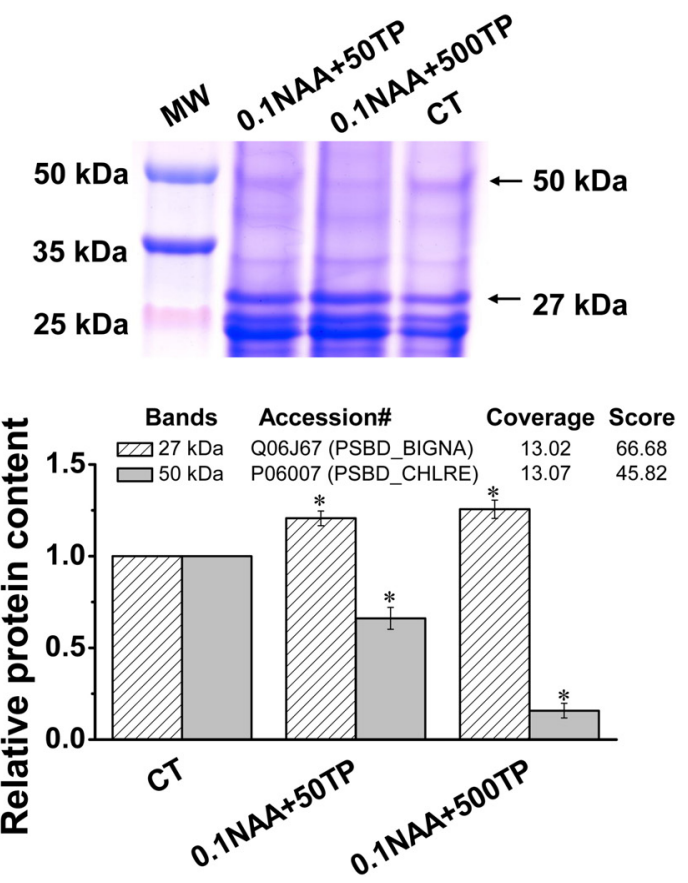

FIGURE 5 | Quantification analysis of photosynthetic proteins of $M$. afer under different culture conditions. (A) Western-blot analyses of D1 protein under different culture conditions. Thylakoid membrane proteins were separated by $12 \%$ SDS-PAGE and subsequently probed with D1 antibody. Thylakoid samples were loaded on the basis of equivalent total protein content $(15 \mu \mathrm{g})$ in each lane. 1/4 CT and 1/2 CT: a fourfold and twofold dilution of extract of control group. (B) The amounts of D1 in M. afer harvested from different culture conditions were calculated based on the gray analysis of western-blot by Image $\mathrm{J}$ software. (C) Isolated thylakoid membrane proteins under different culture conditions on SDS-PAGE. Thylakoid samples were loaded on the basis of equivalent total protein content (15 $\mu \mathrm{g})$ in each lane. (D) Semi-quantification analysis of two target bands $(27$ and $50 \mathrm{kDa})$ according to their gray scale. Values are means $\pm \mathrm{SE}(n=3)$. The insert table showed the protein predicted by LC-MS/MS. Asterisks indicate statistically significant differences compared with the control group $\left({ }^{*} p<0.05\right.$; ANOVA).

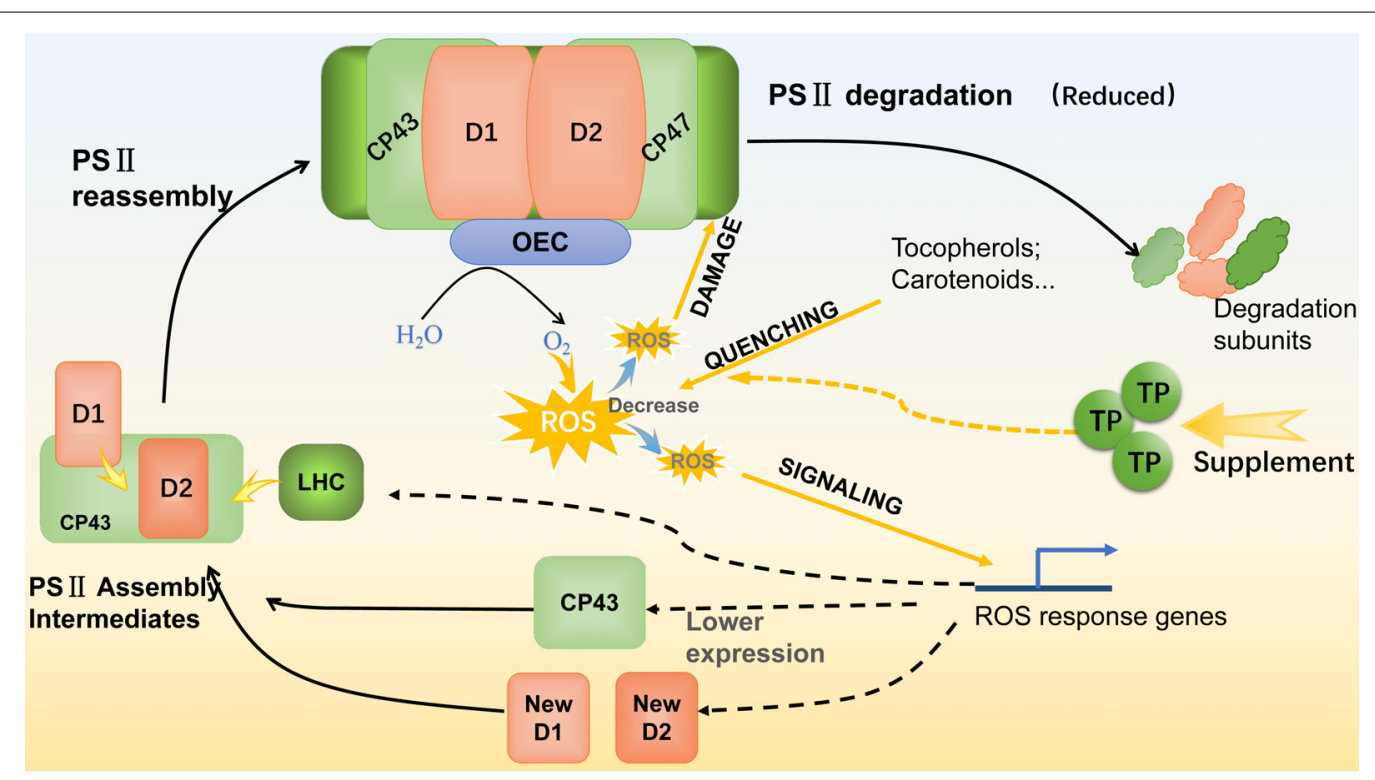

FIGURE 6 | Schematic diagram of the PSII repair cycle under the supplement of TP. With TP supplement, ROS quenching was enhanced and lead to the decrease of ROS for damage and signaling processes. As the result of less ROS damaging, PSIl degradation was reduced and performed as the increasing of D1 and D2 content. For ROS signaling, a less amount of CP43 gives the hint that PSII re-assembly process was decelerated. Colored squares are core protein components (D1, D2, CP43, CP47, LHC, and OEC) of PSII. LHC, light harvesting complex; OEC, oxygen evolving complex. 
(Perrot-Rechenmann, 2010). Nowadays, the presence of auxins in algal lineages were also demonstrated, and parts of their effects on cell growth and development were uncovered ( $\mathrm{Lu}$ and $\mathrm{Xu}, 2015)$. Microalgae might have similar auxin signal and response system of plants (Lau et al., 2009). Auxin signaling, like transport inhibitor response1-auxin signaling F-box protein (TIR1-AFB), auxin response factor (ARF) and auxin-indole-3-acetic acid proteins (AUX-IAA), has been studied (Gray et al., 2001; Tiwari et al., 2003; Parry et al., 2009). Evidence for phytohormone function in microalgae is rare but beginning to accumulate. For instance, auxin was demonstrated to induce cell division in the unicellular desmid Micrasterias thomasiana (Charophyta) and Chlorella pyrenoidosa (Chlorophyta) (Wood and Berliner, 1979; Vance, 1987). Two AUX-IAAs were presented in C. reinhardtii (Palenik et al., 2007). As exogenous synthetic auxin, effects of NAA on the growth and lipid accumulation of $M$. afer were investigated in this study. According to the orthogonal experiments, the cell growth of $M$. afer would be promoted by NAA at the concentration below $1 \mathrm{mg} / \mathrm{L}$, further it was confirmed by the single factor analysis with $0.1 \mathrm{mg} / \mathrm{L}$ NAA treatment. This concentration brought the most significant effect to the growth of $M$. afer at the 2nd day after supplement, which may be due to the regulatory effect of NAA in cell division (Palenik et al., 2007). Furthermore, NAA was stable in the culture system, and had a better growth promoting effect when combined with TP supplement in the later growth stage of M. afer.

The growth and lipid accumulation of $M$. afer were promoted with antioxidant supplement in our study. TP includes catechins, theaflavins, tannins, and flavonoids. Catechins are the main component of TP $(60-80 \%)$, and are mainly composed of EGCG (50\%), epicatechin-3-gallate (ECG, 20\%), epigallocatechin (EGC, 20\%), epicatechin (EC), catechin, and gallocatechin (GC) (Lin et al., 1996; Frei and Higdon, 2003). TP and EGCG were investigated as antioxidant additives in this study, and showed similar effects on $M$. afer growth. Due to the consideration of large-scale production application, TP would be more economical and it was selected for further investigation in this work. With the addition of $0.1 \mathrm{mg} / \mathrm{L}$ $\mathrm{NAA}$ and $500 \mathrm{mg} / \mathrm{L} \mathrm{TP}$, the final lipid yield of $M$. afer was $2.15 \mathrm{~g} / \mathrm{L}$, which was $39.6 \%$ higher than control. The extra fee for additives addition mainly comes from TP, whose price is $60-80 \mathrm{CNY}$ per kilogram for large-scale food grade raw material procurement. It only additional accounted for 15-20 CNY to harvest $1 \mathrm{~kg}$ of algae oil with high NA content (5\%).

With the supplement of NAA and TP, the variation of intracellular ROS level was observed, the changes of photosynthetic efficiency were also significant. As a photosynthetic organism, algae converted light energy into chemical energy for life activities or stored in the form of biochemical compounds. However, the excess light energy could lead to excess ROS accumulation and photo-oxidative damage to the photosynthetic apparatus (Mullineaux and Karpinski, 2002). Photosynthetic organisms need to alleviate the detrimental effects of high ROS stress, especially under stressful conditions (Kolber et al., 1988). In this work, there was an obvious linear relationship between the photosynthetic efficiency and intracellular ROS level. As expected, M. afer cultured with TP was detected a lower ROS level, MDA content, and CAT activity than the control. These indicated that the cells of $M$. afer cultured with TP supplement were under lower oxidant stress (Zhang et al., 2013). The variation of CAT activity was due to the ROS quenching effort of TP, lower activity of CAT is enough for the ROS neutralization. Further analysis of thylakoid membrane proteins by SDS-PAGE and western-blot analysis, the amounts of D1 and D2 proteins in cells cultured with TP were higher than the control, while the amounts of CP43 protein decreased $84.2 \%$ compared with the control. We speculated that TP possesses the function of slowing down the damage of PSII by scavenging excess intracellular ROS and resulting the higher amount of D1 and D2 in the cells. Photo-oxidative damages of PS II are frequently generated by breaking its reaction center and damaging the thylakoid membranes. Organisms maintain the photosynthetic ability through an intricate repair mechanism involving degradation of the damaged D1 reaction center protein and re-assembly by fresh core skeleton proteins into the photosynthetic system (Andersson and Aro, 2001). Under stress conditions, the rate of photo-oxidative damage exceeds the capacity of self-repair, which leads to a decrease of D1 and D2 abundance in photosynthetic system (Krieger-Liszkay et al., 2008). The higher amounts of D1 and D2 proteins might indicated a less degradation of PSII (Erickson et al., 2015). Moreover, instead of the previously known function of CP43, which acted as one of the core PSII antenna proteins. It was also demonstrated the Loop E of CP43 played a crucial role in the assembly of the water oxidizing center during PSII biosynthesis. The structural dynamics of the luminal domain of CP43 determined its role in the assembly of functional PSII centers (Liu et al., 2013). The reduction of CP43 could be associated with the retard of PSII assembly. Based on these, we hypothesis that the ROS level could play a role on the expression of CP43. This was confirmed by our results of ROS analysis. When cells were supplemented with TP, they had a lower ROS level, which lead to a less PSII degradation. Furthermore, the lower ROS level would cause the down-regulation of CP43 protein and less re-assembly of PSII. The regulation pathway from ROS to CP43 is interesting and will be analyzed by future research. In summary, supplement of TP enhanced ROS quenching, therefore the amount of ROS targeted to PSII damage and PSII repair signaling was decreased, which leaded to a less PSII damage (Figure 6). As a result, TP could reduce the damage of PSII by scavenging intracellular excess ROS at later growth stage. The cells supplied with NAA and TP could get higher growth rate, the energy and reducing power could accumulated in the form of fatty acids.

\section{AUTHOR CONTRIBUTIONS}

YF: conceived and designed the experiments. FX, YF, and G-RH: performed the experiments. YF, FM, and JS: analyzed 
the data and discussed the results. YF, FX, F-LL, and GY: wrote the paper.

\section{FUNDING}

This work was supported by China Agriculture Research System (CARS-34), the Forage Industrial Innovation Team, Shandong Modern Agricultural Industrial and Technical System (SDAIT-23-01), and a grant from the National Natural Science Foundation of China (31602154).

\section{REFERENCES}

Andersson, B., and Aro, E.-M. (2001). "Photodamage and D1 protein turnover in photosystem II," in Regulation of Photosynthesis, eds E.-M. Aro and B. Andersson (Berlin: Springer), 377-393. doi: 10.1007/0-306-48148-0_22

Bai, J., Rodriguez, A. M., Melendez, J. A., and Cederbaum, A. I. (1999). Overexpression of catalase in cytosolic or mitochondrial compartment protects HepG2 cells against oxidative injury. J. Biol. Chem. 274, 26217-26224. doi: $10.1074 /$ jbc. 274.37 .26217

Bigogno, C., Khozin-Goldberg, I., Boussiba, S., Vonshak, A., and Cohen, Z. (2002). Lipid and fatty acid composition of the green oleaginous alga Parietochloris incisa, the richest plant source of arachidonic acid. Phytochemistry 60, 497-503. doi: 10.1016/S0031-9422(02)00100-0

Cavas, L., and Yurdakoc, K. (2005). A comparative study: assessment of the antioxidant system in the invasive green alga Caulerpa racemosa and some macrophytes from the Mediterranean. J. Exp. Mar. Biol. Ecol. 321, 35-41. doi: 10.1016/j.jembe.2004.12.035

Chen, W., Zhang, C., Song, L., Sommerfeld, M., and Hu, Q. (2009). A high throughput Nile red method for quantitative measurement of neutral lipids in microalgae. J. Microbiol. Methods 77, 41-47. doi: 10.1016/j.mimet.2009.01.001

Chisti, Y. (2007). Biodiesel from microalgae. Biotechnol. Adv. 25, 294-306 doi: 10.1016/j.biotechadv.2007.02.001

Choo, K. S., Snoeijs, P., and Pedersén, M. (2004). Oxidative stress tolerance in the filamentous green algae Cladophora glomerata and Enteromorpha ahlneriana. J. Exp. Mar. Biol. Ecol. 298, 111-123. doi: 10.1016/j.jembe.2003.08.007

Coupland, K., and Langley, N. A. (1993). Use of nervonic acid and long chain fatty acids for the treatment of demyelinating disorders. U.S. Patent No. 5,194,448. Washington, DC: U.S. Patent and Trademark Office.

Erickson, E., Wakao, S., and Niyogi, K. K. (2015). Light stress and photoprotection in Chlamydomonas reinhardtii. Plant J. 82, 449-465. doi: 10.1111/tpj.12825

Fan, Y., Meng, H. M., Hu, G. R., and Li, F. L. (2018a). Biosynthesis of nervonic acid and perspectives for its production by microalgae and other microorganisms. Appl. Microbiol. Biotechnol. 102, 3027-3035. doi: 10.1007/s00253-0188859-y

Fan, Y., Yuan, C., Jin, Y., Hu, G. R., and Li, F. L. (2018b). Characterization of 3-ketoacyl-coA synthase in a nervonic acid producing oleaginous microalgae Mychonastes afer. Algal Res. 31, 225-231. doi: 10.1016/j.algal.2018.02.017

Frei, B., and Higdon, J. V. (2003). Antioxidant activity of tea polyphenols in vivo: evidence from animal studies. J. Nutr. 133, 3275S-3284S. doi: 10.1093/jn/133. $10.3275 \mathrm{~S}$

Geider, R. J., Roche, J., Greene, R. M., and Olaizola, M. (1993). Response of the photosynthetic apparatus of Phaeodactylum tricornutum (Bacillariophyceae) to nitrate, phosphate, or iron starvation. J. Phycol. 29, 755-766. doi: 10.1111/j. 0022-3646.1993.00755.x

Gray, W. M., Kepinski, S., Rouse, D., Leyser, O., and Estelle, M. (2001). Auxin regulates SCFTIR1-dependent degradation of AUX/IAA proteins. Nature 414, 271-276. doi: 10.1038/35104500

Hu, G., Fan, Y., Zhang, L., Yuan, C., Wang, J., Li, W., et al. (2013). Enhanced lipid productivity and photosynthesis efficiency in a Desmodesmus sp. mutant induced by heavy carbon ions. PLoS One 8:e60700. doi: 10.137/journal.pone. 0060700

Hu, Q., Sommerfeld, M., Jarvis, E., Ghirardi, M., Posewitz, M., Seibert, M., et al. (2008). Microalgal triacylglycerols as feedstocks for biofuel production:

\section{ACKNOWLEDGMENTS}

We thank Eike Krautter for proof reading the manuscript and discussion.

\section{SUPPLEMENTARY MATERIAL}

The Supplementary Material for this article can be found online at: https://www.frontiersin.org/articles/10.3389/fpls.2018.00506/ full\#supplementary-material

perspectives and advances. Plant J. 54, 621-639. doi: 10.1111/j.1365-313X.2008. 03492.x

Ikeuchi, M., and Inoue, Y. (1988). A new 4.8-kDa polypeptide intrinsic to the PS II reaction center, as revealed by modified SDS-PAGE with improved resolution of low-molecular-weight proteins. Plant Cell Physiol. 29, 1233-1239. doi: 10.1093/ oxfordjournals.pcp.a077628

Kato, J., Yamahara, T., Tanaka, K., Takio, S., and Satoh, T. (1997). Characterization of catalase from green algae Chlamydomonas reinhardtii. J. Plant Physiol. 151, 262-268. doi: 10.1016/S0176-1617(97)80251-9

Klughammer, C., and Schreiber, U. (2008). Complementary PS II quantum yields calculated from simple fluorescence parameters measured by PAM fluorometry and the Saturation Pulse method. PAM Appl. Notes 1, 201-247.

Kolber, Z., Zehr, J., and Falkowski, P. (1988). Effects of growth irradiance and nitrogen limitation on photosynthetic energy conversion in photosystem II. Plant Physiol. 88, 923-929. doi: 10.1104/pp.88.3.923

Krieger-Liszkay, A., Fufezan, C., and Trebst, A. (2008). Singlet oxygen production in photosystem II and related protection mechanism. Photosynth. Res. 98, 551-564. doi: 10.1007/s11120-008-9349-3

Lau, S., Shao, N., Bock, R., Jürgens, G., and De Smet, I. (2009). Auxin signaling in algal lineages: fact or myth? Trends Plant Sci. 14, 182-188. doi: 10.1016/j.tplants. 2009.01.004

Li, Y., Han, D., Sommerfeld, M., and Hu, Q. (2011). Photosynthetic carbon partitioning and lipid production in the oleaginous microalga Pseudochlorococcum sp. (Chlorophyceae) under nitrogen-limited conditions. Bioresour. Technol. 102, 123-129. doi: 10.1016/j.biortech.2010.06.036

Lin, Y.-L., Juan, I.-M., Chen, Y.-L., Liang, Y.-C., and Lin, J.-K. (1996). Composition of polyphenols in fresh tea leaves and associations of their oxygen-radicalabsorbing capacity with antiproliferative actions in fibroblast cells. J. Agric. Food Chem. 44, 1387-1394. doi: 10.1021/jf950652k

Liu, F., and Pang, S. J. (2010). Stress tolerance and antioxidant enzymatic activities in the metabolisms of the reactive oxygen species in two intertidal red algae Grateloupia turuturu and Palmaria palmata. J. Exp. Mar. Biol. Ecol. 382, 82-87. doi: 10.1016/j.jembe.2009.11.005

Liu, H., Chen, J., Huang, R. Y.-C., Weisz, D., Gross, M. L., and Pakrasi, H. B. (2013). Mass spectrometry-based footprinting reveals structural dynamics of loop E of the chlorophyll-binding protein CP43 during photosystem II assembly in the cyanobacterium Synechocystis 6803. J. Biol. Chem. 288, 14212-14220. doi: 10.1074/jbc.M113.467613

Liu, J., Dietz, K., DeLoyht, J. M., Pedre, X., Kelkar, D., Kaur, J., et al. (2012a). Impaired adult myelination in the prefrontal cortex of socially isolated mice. Nat. Neurosci. 15, 1621-1623. doi: 10.1038/nn.3263

Liu, J., Yang, H., Lu, Q., Wen, X., Chen, F., Peng, L., et al. (2012b). PSBP-DOMAIN PROTEIN1, a nuclear-encoded thylakoid lumenal protein, is essential for photosystem I assembly in Arabidopsis. Plant Cell 24, 4992-5006. doi: 10.1105/ tpc. 112.106542

Lu, Y., and Xu, J. (2015). Phytohormones in microalgae: a new opportunity for microalgal biotechnology? Trends Plant Sci. 20, 273-282. doi: 10.1016/j.tplants. 2015.01.006

Mittler, R. (2002). Oxidative stress, antioxidants and stress tolerance. Trends Plant Sci. 7, 405-410. doi: 10.1016/S1360-1385(02)02312-9

Mullineaux, P., and Karpinski, S. (2002). Signal transduction in response to excess light: getting out of the chloroplast. Curr. Opin. Plant Biol. 5, 43-48. doi: 10.1016/S1369-5266(01)00226-6 
Munne-Bosch, S. (2005). The role of $\alpha$-tocopherol in plant stress tolerance. J. Plant Physiol. 162, 743-748. doi: 10.1016/j.jplph.2005.04.022

Palenik, B., Grimwood, J., Aerts, A., Rouzé, P., Salamov, A., Putnam, N., et al. (2007). The tiny eukaryote Ostreococcus provides genomic insights into the paradox of plankton speciation. Proc. Natl. Acad. Sci. U.S.A. 104, 7705-7710. doi: 10.1073/pnas.0611046104

Park, W.-K., Yoo, G., Moon, M., Kim, C. W., Choi, Y.-E., and Yang, J.W. (2013). Phytohormone supplementation significantly increases growth of Chlamydomonas reinhardtii cultivated for biodiesel production. Appl. Biochem. Biotechnol. 171, 1128-1142. doi: 10.1007/s12010-013-0386-9

Parry, G., Calderon-Villalobos, L., Prigge, M., Peret, B., Dharmasiri, S., Itoh, H., et al. (2009). Complex regulation of the TIR1/AFB family of auxin receptors. Proc. Natl. Acad. Sci. U.S.A. 106, 22540-22545. doi: 10.1073/pnas.0911967106

Perrot-Rechenmann, C. (2010). Cellular responses to auxin: division versus expansion. Cold Spring Harb. Perspect. Biol. 2:a001446. doi: 10.1101/ cshperspect.a001446

Pinto, E., Sigaud-kutner, T., Leitao, M. A., Okamoto, O. K., Morse, D., and Colepicolo, P. (2003). Heavy metal-induced oxidative stress in algae. J. Phycol. 39, 1008-1018. doi: 10.1111/j.0022-3646.2003.02-193.x

Piotrowska-Niczyporuk, A., and Bajguz, A. (2014). The effect of natural and synthetic auxins on the growth, metabolite content and antioxidant response of green alga Chlorella vulgaris (Trebouxiophyceae). Plant Growth Regul. 73, 57-66. doi: 10.1007/s10725-013-9867-7

Sandhir, R., Khan, M., Chahal, A., and Singh, I. (1998). Localization of nervonic acid $\beta$-oxidation in human and rodent peroxisomes: impaired oxidation in Zellweger syndrome and X-linked adrenoleukodystrophy. J. Lipid Res. 39, 2161-2171.

Sargent, J., Coupland, K., and Wilson, R. (1994). Nervonic acid and demyelinating disease. Med. Hypotheses 42, 237-242. doi: 10.1016/0306-9877(94)90122-8

Schnettger, B., Critchley, C., Santore, U., Graf, M., and Krause, G. (1994). Relationship between photoinhibition of photosynthesis, D1 protein turnover and chloroplast structure: effects of protein synthesis inhibitors. Plant Cell Environ. 17, 55-64. doi: 10.1111/j.1365-3040.1994.tb00265.x

Shi, S., Tang, D., and Liu, Y. (2009). Effects of an algicidal bacterium Pseudomonas mendocina on the growth and antioxidant system of Aphanizomenon flosaquae. Curr. Microbiol. 59, 107-112. doi: 10.1007/s00284-009-9404-0

Tiwari, S. B., Hagen, G., and Guilfoyle, T. (2003). The roles of auxin response factor domains in auxin-responsive transcription. Plant Cell 15, 533-543. doi: $10.1105 /$ tpc.008417
Vance, B. D. (1987). Phytohormone effects on cell division in Chlorella pyrenoidosa chick (TX-7-11-05) (Chlorellaceae). J. Plant Growth Regul. 5, 169-173. doi: $10.1007 / \mathrm{BF} 02087185$

Wellburn, A. R. (1994). The spectral determination of chlorophylls a and b, as well as total carotenoids, using various solvents with spectrophotometers of different resolution. J. Plant Physiol. 144, 307-313. doi: 10.1016/S0176-1617(11) 81192-2

Williams, P. J. L., and Laurens, L. M. L. (2010). Microalgae as biodiesel \& biomass feedstocks: review \& analysis of the biochemistry, energetics \& economics. Energy Environ. Sci. 3, 554-590. doi: 10.1039/B92 $4978 \mathrm{H}$

Wolf, G. (2005). The discovery of the antioxidant function of vitamin E: the contribution of Henry A. Mattill. J. Nutr. 135, 363-366. doi: 10.1093/jn/135. 3.363

Wood, N. L., and Berliner, M. D. (1979). Effects of indoleacetic acid on the desmid Micrasterias thomasiana. Plant Sci. Lett. 16, 285-289. doi: 10.1016/ 0304-4211(79)90040-3

Yuan, C., Liu, J., Fan, Y., Ren, X., Hu, G., and Li, F. (2011). Mychonastes afer HSO-3-1 as a potential new source of biodiesel. Biotechnol. Biofuels 4:47. doi: 10.1186/1754-6834-4-47

Yuan, C., Xu, K., Sun, J., Hu, G. R., and Li, F. L. (2017). Ammonium, nitrate, and urea play different roles for lipid accumulation in the nervonic acid - producing microalgae Mychonastes afer HSO-3-1. J. Appl. Phycol. 1-9. doi: 10.1007/s10811-017-1308-y

Zhang, Y.-M., Chen, H., He, C.-L., and Wang, Q. (2013). Nitrogen starvation induced oxidative stress in an oil-producing green alga Chlorella sorokiniana C3. PLoS One 8:e69225. doi: 10.1371/journal.pone.0069225

Conflict of Interest Statement: The authors declare that the research was conducted in the absence of any commercial or financial relationships that could be construed as a potential conflict of interest.

Copyright $\odot 2018$ Xu, Fan, Miao, Hu, Sun, Yang and Li. This is an open-access article distributed under the terms of the Creative Commons Attribution License (CC BY). The use, distribution or reproduction in other forums is permitted, provided the original author(s) and the copyright owner are credited and that the original publication in this journal is cited, in accordance with accepted academic practice. No use, distribution or reproduction is permitted which does not comply with these terms. 